\title{
SEVEN POINT TWO
}

\author{
Contact has been made.
}

\section{BY MARISSA LINGEN}

$\mathrm{T}$ he astronomers gathered behind the podium, beaming proudly. They had never expected to have so much of the mainstream press at one of their press conferences; most of them had never expected a press conference in the first place. The bright lights of the video cameras made them squint, their smiles slipping into grim desperation even in their moment of triumph.

Cathy Biyu Li had been chosen as the spokesperson, and she spoke. "Good evening. We would like to confirm that we have decoded the broadcast from the unexpected object in the Orion Nebula. Our early reports that it was highly structured have been verified by extensive testing. We now feel extremely confident that this was a communication by an intelligence that was not terrestrial in origin. The communication was as follows -"

"Aliens?" shouted the BBC reporter. "Are you really telling us you have a code from aliens?"

"Yes, that's exactly what I'm saying," said Dr Li. "If you'll let me finish, I can tell you what they were saying."

The reporters took a moment to stop shouting questions and comments. They settled to a buzz, then to silence, as $\mathrm{Dr} \mathrm{Li}$ waited.

"First we had some number sequences, setting the communication with primes and triangular numbers and perfect numbers. This is particularly encouraging because it shows that we have similar concepts of mathematics.

"We have several key ratios that appear in nature: an approximation of twice $\pi$, which shows up in calculating a circumference. That one went out to 20 digits and could not be mistaken for a random number or for something else. We found the ratio of the mass of the proton to the mass of the electron, that one out to ten digits, again not something that would show up randomly. That number, you will note, requires a fairly high degree of scientific measurement, and yet is not dependent upon the units used for that measurement."

The science writers nodded and scribbled quick notes, in their element. They had planned for this, and it was more or less what they expected. The mainstream press squirmed and tried to pay attention, but they had been hoping for more portraits of aliens, and fewer strings of numbers especially with lots of complicated science facts attached to them. The list of numbers droned on.

“... and seven point two," said Dr Li. "Thank you all for coming, we're so glad you could -”

willing to be richly endowed in order to find more of them.

Or at least to pursue them indefinitely.

Meanwhile, Cathy Biyu Li and the other astronomers had kept listening to the signal from the unexpected object in the Orion Nebula. It did not seem to be redshifted or blueshifted compared to the objects around it. It continued to emit a signal, but the signal repeated. Over and over again, so there could be no mistake: here are our constants, here are the things we know about the Universe, the tiniest pieces, the repeating parts. And seven point two.

One of the other astronomers, Dr Jorge Estrada, found Dr Li signalling back to the Orion Nebula one night, late, when no one was around. The same patterns, the same numbers. Maths, physics, the Universe as we know it. And then.

"You're not telling them seven point two. What if they - what if they think we're not sentient, what if they - what was that?" he demanded.

Cathy Biyu Li grinned. "Twelve point nine."

"What are you doing?"

"Aliens are testing us for all sorts of things,

"What's seven point two?" asked the reporter from the Times, who was not afraid of looking stupid. "You explained all the rest of them."

"We're ... not really sure yet. All the others were meaningful. We're looking into it."

Pandemonium among the reporters.

Six months later, 'looking into it' did not begin to cover the worldwide efforts to ascertain the importance of the constant seven point two. Funding for fundamental research skyrocketed. Humanity had been handed a key to the Universe, if only they could find the lock it fit within.

At first the big winners were in physics and chemistry, but over time the planetary scientists/geologists and biologists made their claims known. Surely, they argued, there would be some universality of life processes, some press of rock and sand that remained itself regardless of particulars of atmosphere and temperature. Unitless con- $\rightarrow$ NATURE.COM

Follow Futures: y @NatureFutures f go.nature.com/mtoodm powerful things in the world, but every university's science departments were stants were rare and
Jorge. Curiosity, mathematical ability, advancement in the physical sciences."

"Yes, of course, we'd be looking for all of those things."

"And maybe seven point two is there to get us looking farther. To stimulate us, even if there's nothing to it."

Jorge nodded; this was a popular theory among the astronomers.

"But maybe," Cathy continued. "Maybe they're testing for something else. Maybe it's their little joke. Children love randomness. If you want to make a baby laugh, do something funny. Unexpected. Seven point two? Hah, that's a good one. You want to hear another one? Twelve point nine!"

She chortled. He stared at her blankly. "I don't get it." He wandered off, shaking his head angrily and muttering about the committee.

"No," she whispered. "But in another couple of thousand light years, someone else is going to get a good laugh out of it."

Marissa Lingen has published more than 100 short stories in venues such as Analog, Lightspeed and Tor.com. 